\title{
CONSTRUINDO 0 ROTEIRO DE ENTREVISTA NA PESQUISA EM REPRESENTAÇÕES SOCIAIS: COMO, POR QUE, PARA QUE
}

\author{
Building the script of an interview on social representations research: how, why, what \\ for \\ Construyendo el guión de entrevista en la investigación en representaciones sociales: \\ cómo, por qué, para qué
}

\section{RESUMO}

Revisão bibliográfica sobre a construção do roteiro de entrevista aplicado à pesquisa no campo das representações sociais, a partir do levantamento dos elementos essenciais à sua elaboração. Realizaram-se busca em base de dados virtual e em uma biblioteca setorial; seleção de obras de referência e periódicos de indexação; e leitura seletiva e analítica. As perguntas, avançando do particular e concreto para o geral e abstrato, devem fazer emergir informações, imagens, crenças, opiniões; abordar aspectos do cotidiano prático dos sujeitos, além de caracterizá-lo para compreender o grupo no sujeito e o sujeito no grupo, assim como captar a zona muda da representação. Conclui-se que o modo de coleta dos dados conduz e interfere na captação de representações. Assim, este estudo fornece subsídios teórico-metodológicos, e indica a importância da vigilância epistemológica nas pesquisas deste campo.

Palavras-chave: Enfermagem. Pesquisa. Entrevista. Psicologia social.

\begin{abstract}
Bibliographic revision about the building of a script of interview applied to research in social representations field, from the survey of elements that are essential to its elaboration. A search was held on a virtual data base and at a sectorial library; selection of reference books and indexed publications; selective and analytical reading.

The questions, going from the private and concrete to the general and abstract, should emerge information, images, beliefs, opinions; approach aspects of the practical daily lives of the individuals, besides characterizing it to understand the group in the individual and the individual in the group, as well as to catch the mute zone of the representation. It is concluded that the way the data are collected leads and interferes on getting the representations. Therefore, this study provides theoreticalmethodological subsidies, and indicates the importance of epistemological vigilance in the researches of this area.
\end{abstract}

Keywords: Nursing. Research. Interview. Social Psychology.

\section{Resumen}

Revisión bibliográfica sobre la construcción del guión de entrevista aplicado a la investigación en el campo de las representaciones sociales, a partir de la recorrida de los elementos esenciales a su elaboración. Ha sido realizada una búsqueda en la base de datos virtuales y en una biblioteca sectorial; selección de obras de referencia y periódicos de indexación; lectura selectiva y analítica. Las preguntas, al avanzar del particular y concreto para el general y abstracto, deben hacer emerger informaciones, imágenes, creencias, opiniones; abordar los aspectos del cotidiano práctico de los sujetos, además de caracterizarlo para comprender el grupo en el sujeto y el sujeto en el grupo, así como captar la zona muda de la representación. Se concluye que la manera de recolectar los datos conduce e interfiere en la captación de representaciones. Así, este estudio fornece subsidios teóricos y metodológicos, e indica la importancia de la vigilancia epistemológica en las investigaciones de este campo.

Palabras claves: Enfermería. Investigación. Entrevista. Psicología social.

${ }^{1}$ Enfermeiro. Mestre em Enfermagem. Aluno do Curso de Doutorado da Escola de Enfermagem Anna Nery/EEAN - UFRJ. Professor Assistente do Departamento de Enfermagem Fundamental da EEAN/UFRJ. Membro do Núcleo de Pesquisa de Fundamentos do Cuidado de Enfermagem (Nuclearte). Rio de Janeiro-RJ. Brasil. E-mail: rafaenfer@yahoo.com.br,'²Enfermeira. Doutora em Enfermagem. Professora Titular do Departamento de Enfermagem Fundamental da EEAN/UFRJ. Membro do Núcleo de Pesquisa de Fundamentos do Cuidado de Enfermagem (Nuclearte). Pesquisadora do CNPQ. Rio de Janerio-RJ. Brasil. E-mail: marciadeaf@ibest.com.br 


\section{INTRODUÇÃO}

A construção de uma pesquisa envolve a criteriosa observação de aspectos importantes, no que diz respeito ao rigor científico dos elementos fundamentais que a compõem, isto é, a delimitação do problema e objeto de investigação, a definição dos objetivos, bem como a descrição do caminho metodológico a ser seguido.

A forma de desenvolvimento destas etapas encontrase intimamente relacionada com a qualidade das informações a serem produzidas e, consequentemente, com a validade do conhecimento gerado. No caso dos estudos no campo das representações sociais (RS), os elementos principais na construção do objeto de pesquisa são fenômeno, teoria e método ${ }^{1}$, e esta construção é vista como um processo decisório, pelo qual transforma-se conceitualmente um fenômeno do universo consensual em um problema do universo reificado e, em seguida, selecionam-se os recursos teóricos e metodológicos para a solução do problema ${ }^{1}$.

Neste contexto, considera-se também a necessidade de um instrumento de coleta de dados substanciado, fundamentado, informado pelo referencial teórico à luz do qual a pesquisa se constrói, pois, caso contrário, os dados gerados não possibilitarão uma análise que se traduza em informações que atendam aos objetivos propostos.

No caso da pesquisa em tela, destaca-se a relevância do roteiro de entrevista. A produção de informações a partir do uso de material espontâneo, à exemplo das entrevistas, possibilita a observação das pessoas em seus próprios territórios, bem como a interação com estas através de sua própria linguagem e em seus termos. Então, entendendo que a conversação está no epicentro do universo consensual, porque ela molda e anima as RS e assim Ihes dá vida própria ${ }^{2}$, é que se ressalta a importância das entrevistas enquanto técnica de coleta de dados para a pesquisa sobre RS.

Contudo, percebe-se que os alunos, de um modo geral, seja de cursos de graduação ou até mesmo de pós-graduação, encontram dificuldades na elaboração das questões que irão constituir o roteiro de entrevista na pesquisa científica, o que gera inquietação e ansiedade, no sentido de propor perguntas que sejam realmente importantes, de significação clara e precisa, que não sugiram respostas aos entrevistados, enfim, que proporcionem uma liberdade de expressão aos sujeitos, ao tempo em que lhes possibilitem responder à questão-problema que se coloca.

Nas pesquisas conduzidas pela Teoria das Representações Sociais (TRS), os debates frequentes da comunidade científica acerca da quantidade de questões do roteiro, de sua ordem lógica, da "massa" de dados para serem analisados, da forma de construção das perguntas, às quais muitas vezes o entrevistado não responde sobre si, mas sobre como 0 outro agiria em determinada situação, colocam 0 pesquisador diante de uma série de embates teóricos. Aliada a isso, destaca-se a dispersão na literatura acerca dos elementos essenciais que devem constituir um instrumento de entrevista de perspectiva psicossociológica, o que reforça a necessidade de discussões que procurem estratégias para facilitar a prática de pesquisa em relação a este aspecto.

Neste sentido, este estudo objetiva discutir sobre a construção do roteiro de entrevista aplicado à pesquisa no campo das representações sociais, a partir do levantamento dos elementos essenciais à sua elaboração.

\section{METODOLOGIA}

Pesquisa do tipo revisão bibliográfica, que envolveu a realização das seguintes etapas: levantamento preliminar em base de dados em meio virtual, aliado a buscas manuais em uma biblioteca setorial de pós-graduação em enfermagem. Para tanto, foram identificadas e selecionadas obras de referência no que diz respeito à TRS e periódicos de indexação. A localização destas fontes deu-se mediante visita à Biblioteca da Pós-Graduação da Escola de Enfermagem Anna Nery (EEAN/ UFRJ), bem como em bases de dados virtuais como Scielo, Lilacs, Medline e BDENF, pelo emprego das palavras-chave: representações sociais e entrevista, sem um intervalo de tempo determinado para a busca, haja vista o baixo número de publicações de abordagem teórico-metodológica nesta área. Os estudos obtidos inicialmente sofreram um refinamento a partir da identificação daqueles que preenchiam aos critérios de inclusão desta pesquisa, à luz do objetivo pretendido. 0 passo seguinte foi a leitura exploratória das obras selecionadas, com o intuito de identificar a aderência destas à pesquisa em tela. Posteriormente, os estudos elencados sofreram nova classificação, a partir da leitura seletiva e analítica, às quais se configuraram em uma leitura crítica em que houve 0 ordenamento e classificação das informações contidas nas fontes, de modo a ver aquilo que possibilitaria o alcance dos objetivos propostos. Tal fase possibilitou decidir por aqueles que seriam, então, incluídos na pesquisa, compondo assim um quantitativo de 15 trabalhos, os quais foram submetidos à leitura interpretativa, de modo a conferir significado aos dados. As categorias foram organizadas mediante a análise temática dos conteúdos extraídos dos materiais consultados.

\section{PENSANDO NO INST RUMENTO A PARTIR DO REFERENCIAL TEÓRICO}

A partir da análise do material que serviu de referência para esta investigação, evidenciou-se uma tendência majoritária na bibliografia, apontando que na construção do instrumento de coleta de dados, alguns elementos teóricos devem ser levados em consideração, no intento de que as questões formuladas possibilitem apreender aspectos indicativos das representações sociais. Neste sentido, esta categoria temática objetiva apresentar alguns fundamentos teóricos relevantes para a pesquisa de RS, os quais devem nortear a elaboração do 
roteiro de entrevista, e que ganharam destaque a partir da análise bibliográfica.

Nesta perspectiva, destaca-se inicialmente, que o estudo das RS remete a duas importantes discussões: 1) as representações emergem como uma modalidade de conhecimento prático orientado para a compreensão do mundo e para a comunicação; 2) surgem como construções, com caráter expressivo, elaborações de sujeitos sociais sobre objetos socialmente valorizados. Assim, as RS devem ser entendidas como estruturas cognitivo-afetivas que envolvem tanto um conteúdo cognitivo quanto uma compreensão a partir do contexto que as engendram e a partir de sua funcionalidade nas interações sociais do cotidiano $^{3}$.

Com base neste conceito, os estudos utilizados nesta revisão sinalizaram que, quando se pensa na coleta de dados, deve-se buscar abarcar os elementos e relações contidos em uma representação social. Para tanto é necessário estabelecer interfaces com três questões: quem sabe, e a partir de onde sabe? 0 que e como sabe? Sobre o que sabe, e com que efeitos? A partir de tais perguntas, é possível então chegar a 3 planos: 1) as condições de produção e circulação das representações sociais; 2) os processos e estados das representações sociais; 3) 0 estatuto epistemológico das representações sociais ${ }^{4}$.

Captar os processos e estados da representação social significa apreender as dimensões da representação: seu campo estruturado, a atitude que carrega e que lhe dá o componente afetivo, o elemento da informação que ela contém. 0 campo das RS é entendido como um campo estruturado de significações, saberes e informações. Isto implica envolver as expressões, imagens, ideias e valores presentes no discurso sobre o objeto. Assim, pensar neste aspecto teórico possibilita caracterizar como se dá a construção da representação, sua gênese, processos de elaboração e constituição ${ }^{4}$.

Quanto às condições de produção da representação, afirma-se que o seu delineamento permite explicar o sentido que os grupos atribuem ao objeto representado. Parte-se assim do entendimento de que toda representação se origina de alguém, que é um sujeito social, imerso em condições específicas de seu espaço e tempo, e refere-se a um objeto. Tais condições de produção referem-se, portanto, à cultura, no sentido amplo e restrito, à comunicação e linguagem, e à inserção econômica, institucional, educacional e ideológica. Desta forma, identificar as condições de produção a partir de estratégias de coleta de dados é destacar a marca social das representações ${ }^{4}$.

Já no que tange ao estatuto epistemológico da representação, este se refere à relação da representação com o real; isto é, a representação se constrói na tentativa de atender as necessidades, interesses de um determinado grupo, sendo, portanto, um conhecimento sociocêntrico.
Assim, ao atentar para o estatuto epistemológico compreendese como e por que acontecem determinadas subtrações ou acréscimos de elementos ao objeto representado, o que elas indicam e como elas constituem a representação, conferindo a ela um sentido de verdade e eficácia simbólica ${ }^{4}$. Envolve então, os aspectos normativos, valores de quem representa, e o imaginário do sujeito.

Ressaltou-se ainda, nos artigos e livros, a construção dos fenômenos de natureza psicossociológica. Sobre isso, vale citar que a representação é uma estrutura que medeia a relação sujeito-outro, sujeito-objeto, por meio da ação comunicativa. Neste sentido, entende-se que a representação social está imersa na ação comunicativa, isto é, a ação comunicativa, forma em um mesmo e único processo os seus participantes. 0 trabalho comunicativo da representação gera símbolos que fornecem sentido, dão significado. Desta forma, trabalha colocando algo no lugar de algo, promovendo um deslocamento simbólico ${ }^{5}$.

Tal afirmação permite dizer que nem todo assunto se torna um objeto de representação social para o grupo e nem todos os fenômenos são tributários de converterem-se em problemas de pesquisa de representação social ${ }^{6}$. Logo, um estudo que traz um objeto que não se sustenta enquanto fenômeno de representação social, ou define um grupo de pertença que não se constitui socialmente relevante em relação a um determinado fenômeno, não contribui para a (re)produção de representações. Entender esta natureza da teoria possibilita a correta abordagem do fenômeno no momento de elaboração do roteiro de entrevista.

\section{ELEMENTOS ESSENCIAIS NA CONSTRUÇÃO DO ROTEIRO DE ENTREVISTA}

Tomando como eixo norteador o corpus de análise desta pesquisa, intenta-se, a partir deste momento, destacar as características principais de um roteiro de entrevista, para os estudos no campo das RS. Desta feita, trazem-se ao debate alguns elementos que vêm sendo discutidos pelos teóricos desta área, e que conformaram esta categoria mediante a análise temática de conteúdos extraídos da bibliografia consultada.

Um dos aspectos desta discussão, que pôde ser percebido no material analisado, relaciona-se à ordem e ao tipo de questões a serem feitas. Nesta perspectiva, evidenciou-se que, de modo geral, um instrumento deve partir de perguntas que levantem aspectos do objeto de representação de níveis mais concretos, familiares e definidos até os mais abstratos, estranhos e ambíguos ${ }^{2}$. Na pesquisa acerca da loucura, referência nos estudos de RS e base para o desenvolvimento da teoria, utilizou-se para coleta dos dados a entrevista, a qual, no intento de atender às características das RS enquanto sistemas cognitivos, procurou "cercar" as representações avançando do particular e concreto (as práticas cotidianas nos albergues) para o geral e abstrato, com perguntas envolvendo reflexões e julgamentos (as representações da doença mental)7 
Quanto à linguagem a ser utilizada na elaboração das perguntas, os estudos utilizados indicam a possibilidade de abordagem por duas correntes. Na primeira, ressalta-se que é fundamental utilizar uma linguagem que se aproxima do contexto natural no qual o fenômeno se manifesta, ou seja, o material do qual se queira extrair as representações deve ser produzido pelos sujeitos da forma mais espontânea possível? Contudo, a fiel reprodução de uma realidade nem sempre é necessária para desencadear o fluxo simbólico e existencial, apontando para outra corrente em que se defende que a espontaneidade não é uma garantia de ampla revelação das representações, podendo mesmo ter, ao contrário, o efeito de encobri-las".

De acordo com o posicionamento destes teóricos, as perguntas da entrevista devem ser formuladas de modo a avançarem além da espontaneidade em direção a aspectos que por diversas razões não são ditos, uma vez que o não dito pode constituir-se no principal conteúdo da representação!. Defende-se a ideia de que, em certas situações, para certos objetos, exista uma zona muda de representação social.

Esta zona muda constitui-se de uma segunda parte da representação, composta de elementos que não são verbalizáveis pelos sujeitos entrevistados. A zona muda é composta de elementos da representação que são "contranormativos", ou seja, cognições ou crenças que não são expressas pelo sujeito em condições normais de produção, pois podem entrar em conflito com valores morais ou normas do grupo ${ }^{8}$.

A fim de procurar saber o que está escondido, ou seja, na intenção de conseguir revelar os elementos da zona muda de representação, é preciso aplicar métodos específicos de investigação, buscando identificar a existência ou não da zona muda, como é o caso da técnica de substituição e descontextualização normativa.

A técnica de substituição baseia-se na ideia de que um sujeito poderá exprimir representações "proibidas ao seu grupo" atribuindo-as a outros, isto é, falando por outros. A primeira etapa consiste em responder em seu próprio nome, pedindo-se à pessoa que dê sua própria opinião sobre um tema; e, a seguir, pede-se que responda no lugar dos outros, isto é, imagine e diga como um outro faria quando interrogado pelo mesmo tema, reduzindo seu nível de implicação. 0 outro deve ser relacionado ao grupo de referência do sujeito. A técnica de descontextualização normativa consiste em manipular 0 receptor das respostas do sujeito, ou seja, refere-se a uma condição na qual o entrevistado pensa estar respondendo a um pesquisador que não pertence ao seu grupo de referência em relação o objeto. Postula-se que será mais fácil ao sujeito responder expressando suas ideias desviantes, contranormativas, em face de uma pessoa menos próxima e que não partilha do mesmo sistema de referênciå.

Ainda na tentativa de discutir alguns aspectos da entrevista, os estudos enfatizam que questões de definição devem ser evitadas, visto que este tipo de questão não possibilita ter acesso às suas representaç̃̃es, mas no máximo à maneira como ele se representa, que convenha cientificizar a noção $0^{9}$. Propõe-se então que as perguntas sejam formuladas de modo a deixar lugar para os julgamentos de valores, já que, compreendendo as RS enquanto guias para a ação, não se pode separar o aspecto cognitivo do afetivo. Assim, o sujeito deve perpassar por três níveis de representações, de complexidade crescente: as imagens mentais, as representações referenciais e os sistemas de relações. É apenas no interior de um sistema de relações que é possível superar a pura análise dos conteúdos para extrair verdadeiras organizações cognitivas ${ }^{9}$.

Uma vez que a representação é elaborada coletivamente a partir das trocas e práticas cotidianas de um determinado contexto histórico, ela acaba fornecendo subsídios para os julgamentos e atitudes. A representação funciona como pano de fundo das atitudes dos indivíduos, dando sentido ao universo vivido ${ }^{10}$. Desta feita, o roteiro de entrevista deve ser capaz de rastrear a dimensão da atitude por meio de questionamentos que permitam que o sujeito expresse suas escolhas e decisões, e capte as posições dos sujeitos diante das situações do cotidiano relacionadas ao objeto estudado.

\section{ARTICULANDO TEORIA E PRÁTICA NA ELABORAÇÃO DO ROTEIRO DE ENTREVISTA}

Na tentativa de melhor visualização da aplicabilidade dos aspectos elencados à construção do instrumento de entrevista, propõe-se apresentar nesta categoria, um ensaio sistematizado de elaboração do roteiro, tendo como referência um estudo desenvolvido no campo da saúde, acerca das RS dos enfermeiros que atuam na assistência ao cliente em ambientes de cuidados intensivos, sobre a tecnologia inserida neste cenário. Tal estudo utilizou a vertente processual da TRS, e foi realizado na Unidade Cardiointensiva de uma instituição pública federal, tendo como instrumentos de coleta de dados a entrevista semiestruturada e a observação sistemática ${ }^{11}$.

Considerando que as representações sociais são uma modalidade de conhecimento prático, as perguntas precisam versar sobre a concretude do fenômeno que se estuda, ou seja, o instrumento deve abordar aspectos do cotidiano prático dos sujeitos que se inter-relacionam com tal fenômeno, no intuito de buscar captar os elementos que compõem e estruturam a representação. Exemplificando este aspecto, são apresentadas as seguintes questões: Como é para você trabalhar em um setor como este, de alta tecnologia? Fale sobre sua experiência; Há alguma diferença entre cuidar de um cliente que não precisa desta tecnologia e cuidar de um que precisa dela? Que diferenças são essas?

Entendendo que as RS são uma forma de conhecimento social, evidencia-se a necessidade de o instrumento tentar acessar as condições de produção da representação social, ou seja, quem é o sujeito, de onde vem e de onde fala, o que instrui 
seu pensamento e ação. A este respeito, a pesquisa tomada como exemplo procurou desenvolver um roteiro de coleta de dados sociodemográficos, com vistas a caracterizar o sujeito em relação ao fenômeno representado. Neste sentido, buscou-se identificar tanto os dados pessoais (sexo, idade, religião) quanto os profissionais (número de empregos, tempo de formação, qualificação, regime/turno de trabalho, experiência).

No que tange ao campo em que se estrutura a representação, ou melhor, quanto ao conteúdo que define a representação, torna-se fundamental que se insiram perguntas suficientemente adequadas para evidenciar os elementos que integram o campo da representação, ou seja, as informações, imagens, opiniões, atitudes. Então, questionou-se: Você acha que a tecnologia influencia no cuidado prestado ao cliente crítico? Como? Que influência ela exerce? Trabalhar com tecnologia mudou alguma coisa para você? Alguma coisa te preocupa em relação à tecnologia no cuidado?

Uma vez que o grupo exprime seus contornos e sua identidade pelo sentido investido na representação, o roteiro deve conter questões que visem compreender o grupo no sujeito e o sujeito no grupo. Para abarcar esta característica, interrogouse: Como é ser enfermeiro em um setor com alta tecnologia? Quem pode trabalhar em um setor como este? Existe um tipo ideal de enfermeiro para trabalhar neste setor?

Em última instância, compreendendo que em um roteiro de entrevista deve-se abordar a zona muda das representações, foram delineadas as seguintes inquirições: 0 que você acha que as pessoas pensam sobre um setor de alta tecnologia? 0 que você acha que as pessoas pensam da enfermeira que atua em um setor de alta tecnologia?

\section{O MAPEAMENTO DAS RS A PARTIR DA ENTREVISTA: UMA CONTRIBUIÇÃO PARA A ENFERMAGEM}

A TRS vem se destacando como uma teoria explicativa da realidade, ocupando um espaço importante na psicologia social. Desponta como um referencial teórico muito utilizado em outros campos, que procuram nesta disciplina elementos elucidativos para os seus objetos específicos, como é o caso da saúde. Esta aplicação se dá principalmente na tentativa de acessar os saberes que orientam as práticas da população acerca dos problemas de saúde. Tal perspectiva teórica vem sendo usada para análise do processo saúde/doença desde o clássico trabalho de Herzlich em 1969'12.

Na enfermagem, em especial, há uma apropriação da TRS com uma orientação própria, ou seja, condiciona a pesquisa à sua utilidade para intervenção, reconhecendo a legitimidade do saber do senso comum, percebido como fundamental para o processo de cuidar da enfermagem ${ }^{12}$. $\grave{A}$ luz desta afiliação teórico-conceitual o sujeito é visto como uma ator social no processo de elaboração das ideias, e as representações como motor das transformações sociais ${ }^{13}$.
Logo, isso implica salientar a necessidade de acessar os saberes e entender as práticas populares de cuidado que deles derivam. No caso da educação em saúde, por exemplo, esta seria uma condição sine qua non para uma prática de perspectiva libertadora, dialógica e promotora da autonomia dos sujeitos no cuidado de $\mathrm{si}^{14}$.

Assim, cada vez mais profissionais da saúde coletiva e enfermagem têm se utilizado do referencial teórico das RS em suas pesquisas, partindo de temas que não só dizem respeito às doenças, mas também ao entendimento das questões em torno do cuidado. A enfermagem, então, na tentativa de entender, conhecer, melhor visualizar aspectos do cuidado de enfermagem, vem despontando como área de conhecimento que traz importantes elementos teóricos que contribuem para o avanço da teoria.

Portanto, a TRS pode ser útil não somente para o esclarecimento das nuances do processo saúde-doença, mas também ajuda a entender aspectos inerentes à profissão, situando-a no contexto histórico-social, entendendo a dinâmica de suas práticas ${ }^{15}$.

No processo de mapeamento das RS, compreende-se que estas são resultantes de um contínuo burburinho e um diálogo permanente entre indivíduos, um diálogo que é tanto interno quanto externo, e durante o qual as representações individuais ecoam ou são complementadas ${ }^{2}$. Sob esta perspectiva, salientam-se as contribuições da entrevista, no sentido de possibilitar que o pesquisador consiga acessar esse diálogo incessante dos sujeitos, sobre os fenômenos de interesse da saúde.

\section{CONCLUSÃO}

0 debate proposto neste artigo surge em um momento em que muito se questiona sobre como elaborar perguntas, que tornem possível a identificação das RS. Configurou-se, assim, como um exercício inicial de reflexão acerca dos elementos que requerem atenção e cuidado quando da elaboração do roteiro. Com base nos resultados, reitera-se a ideia de que se deve fomentar a estruturação do roteiro de entrevista a partir da inter-relação com a teoria em que se fundamenta, no intento de trazer subsídios para a construção do conhecimento, mormente para a enfermagem.

Conclui-se que o modo de coleta dos dados pode interferir na forma como as representações aparecem. Ao discutir a entrevista como uma das técnicas qualitativas em que se deve investir, reitera-se a importância deste estudo que ora se apresenta, na medida em que fornece subsídios teórico-metodológicos para a pesquisa neste campo, e indica a necessária vigilância epistemológica que deve acompanhar os pesquisadores durante o processo de investigação, no sentido de avaliar a pertinência e adequação do instrumento de entrevista aos objetivos e ao referencial teórico em que se apoia. 


\section{REFERÊNCIAS}

1.Sá CP. Construção do objeto de pesquisa em representações sociais. Rio de Janeiro:EdUERJ; 1998.

2. Spink MJP. Estudo empírico das representações sociais. In: Spink MJP, organizadora. 0 conhecimento no cotidiano: as representações sociais na perspectiva da psicologia social. São Paulo: Brasiliense; 1995. p. 86108.

3. Jodelet D. As representações sociais. In: Jodelet D, organizadora. Representações sociais: um domínio em expansão. Tradução de Lilian Ulup. Rio de Janeiro: EdUERJ; 2001. p.18-26.

4. Arruda A. Teoria das representações sociais e teorias de gênero. Cadernos de Pesquisa. 2002 nov; (117): 127-47.

5. Jovchelovitch S. Psicologia social, saber, comunidade e cultura. Psicol Soc. 2004 maio/ago; 16(2): 20-31.

6. Teixeira MCTV, Schulze CMN, Camargo BV. Representações sociais sobre a saúde na velhice: um diagnóstico psicossocial na rede básica de saúde. Estud Psicol. [on-line] 2002 jul/dez; 7(2): [citado 2009 set 26]: [aprox. 13 telas]. Disponível em: http:// www.scielo.br

7. Jodelet D. Loucuras e representações sociais. Petrópolis(RJ): Vozes; 2005.

8. Menin MSS. Representação social e estereótipo: a zona muda das representações sociais. Psicol 2006 jan/abr; 22(1): 43-52.

9. Grize JB. Lógica natural e representações sociais. In: Jodelet D, organizadora. As representações sociais. Rio de Janeiro; EdUERJ; 2001. p.126-37.

10. Espíndula DHP, Santos MFS. Representações sobre a adolescência a partir da ótica dos educadores sociais de adolescentes em conflito com a lei. Psicol Estud. 2004 set/dez ; 9(3): 357-67.

11. Silva RC, Ferreira MA. Representações sociais dos enfermeiros sobre a tecnologia no ambiente da terapia intensiva. Texto\&Contexto Enferm. 2009 jul/set; 18(3): 489-97.

12. Oliveira DC, Rodrigues BMRD. A utilização da teoria das representações sociais no campo da enfermagem: uma busca de aproximação. Rev Enferm UERJ. 2001 set/dez; 9(3): 260-69.

13. Ferreira MA, Figueiredo NMA, Arruda A, Alvim NAT. Cuidados fundamentais de enfermagem na ótica do cliente: uma contribuição para a enfermagem fundamental. Esc Anna Nery. 2002 dez; 6(3): 387-96.

14. Ferreira MA, Alvim NA, Teixeira MLO, Veloso RC. Saberes de adolescentes: estilo de vida e cuidado à saúde. Texto\&Contexto Enferm. 2007 abr/jun; 16 (2): 217-24.

15. Ferreira SRS, Brum JLR. As representações sociais e suas contribuições no campo da saúde. Rev Gauch Enferm. 2000; 20 (n.esp.): 5-14. 